\title{
Study on the Incentive Strategies of Graduate Students in University Research Team
}

\author{
LIU Tingting \\ School of Mechanical Engineering \\ Hangzhou Dianzi University \\ Hangzhou, China \\ Liutingting817@163.com
}

\author{
CHEN Guojin \\ School of Mechanical Engineering \\ Hangzhou Dianzi University \\ Hangzhou, China
}

\begin{abstract}
In this paper, the graduate students in university scientific research team as the research objects, their individual needs are analyzed and the practical incentive strategies that suitable for the scientific research team in China's colleges and universities are explored. In order to mobilize the enthusiasm of students in study and research, we should make full use of their research potential and steadily improve the quality of postgraduate training. The incentive strategies of material incentive, work design incentive, model incentive, academic innovation incentive and personal growth and development incentive are innovations of this paper, compared with the traditional teaching cultivation; the new methods have played good effect.
\end{abstract}

Keywords—research team; graduate students; incentive strategy; research potential

\section{INTRODUCTION}

Colleges and universities as the main positions of science and education, undertake the dual task of scientific innovation and the training of technology professionals. Graduate Students as the main force of technological innovation, the training level represents a nation's education and development level of science and technology. Integrate graduate training to the research team become a new mode of graduate education. Under the guidance of this model, graduate students directly involved in the scientific research of team work, both cultivate their ability to scientific research, but also cultivate their team spirit, better achieve the combination of teaching and research, technological innovation and personnel training. While many colleges and universities recognize the importance of postgraduates training, as the vulnerable groups in the research team, if the reasonable requirements are not met, it will affect the initiative and enthusiasm of learning and research, which will affect the entire team atmosphere of scientific research. As the most active technology innovation, in order to give full play to research potential of graduate students, the research team must pay attention to the parties face effect of graduate students. This paper is based on the problems in postgraduate training, stimulate research initiative and creativity of graduate students and widen the space for their own development [1][2].

\section{NEEDS ANALYSIS OF GRADUATE STUDENTS AND SIGNIFICANCE OF INCENTIVE}

At present, the research on the motivation of the graduate students in China is mainly on the teaching management, and on the basis, further analysis of how to improve the enthusiasm and learning initiative, discuss the external environment and system construction. For example, Dr. Linglin Hu discussed the relationship between the subject and object in the practice of teaching to explore the cultivation of graduate students; Jianjun Yan analyzed the science management system, culture and other aspects of the science and technology university, then established an effective incentive mechanism. There are also a number of issues involved in the graduate students' tutor system, the employment problems and the research and innovation cultivation of graduate students. These cultivation are mainly concerned with the importance of teaching, but neglect the function of scientific research and innovation; some of the papers mentioned in the research practice to cultivate student's ability but did not pay attention to the importance of scientific research team; some noticed the research team as a platform to develop the students' research ability but did not pay attention to the incentive measures. Therefore, the study of the students' incentive strategy is still in the preliminary stage.

\section{A. Needs analysis of Graduate students}

Graduate students, especially high school graduate, are important parts of the research team in colleges and universities in China, they are not only learners, but also researchers, they are responsible for science and technology innovation. Excellent research team can provide a favorable environment for the growth of graduate students, the graduate students integrating into the research team is the new model of graduate education. On the other hand, graduate students in the research team are relatively weak to the other members, they have the characteristics of mature, strong sense of responsibility, diverse circumstances, high knowledge level, rational analysis capability, the pursuit of higher self value, which determines the university graduate students have their own characteristics and needs, they are more mature, more eager to have a challenging work, more eager to realize the value of themselves.

\section{B. Significance of the research team incentive}

Under pressure from the increasingly high living cost and their own growth and development, if their reasonable 
requirements are not met, the initiative of learning and research can not be fully exploited, it is bound to affect the overall atmosphere of the research team.

1) Research team incentive can mobilize the initiative of students, stimulate their creativity

As important members of the research team, the graduate students have formed an integrated system with the other members. The characteristics of age structure and knowledge structure determine that they have a strong desire for knowledge, they have the need for self-worth and the challenge to the scientific research. The effective incentive can let the graduate students full of research enthusiasm, willing to devote a lot of energy to study their subjects. Great inherent power can stimulate their creative potential in learning and scientific research, as well as in their future work, the graduate will show the spirit of not afraid of difficulties, courage and initiative, this motivation can also help students maintain their enduring love for education. American psychologist Professor William.James has carried on the incentive test, he found that under the conditions of hourly wage, a person without stimulation can only play $20 \%$ - 30\% of his capacity, if proper and adequate incented, he can play $80 \%-90 \%$ of his capacity.

2) Research team incentive can enhance team spirit of graduates

Graduate students directly involved in scientific research tasks, this model has been a breakthrough to the tutor individual guidance, then form a collective guidance under the supervisor. The graduate students are not only learners, but also the researchers, in order to achieve the combination of teaching and scientific research, technology innovation and personnel training. In the research team, graduate students can make full use of their own potential and creativity, but also can cooperate with each other, work together, which is a great challenge to the students' knowledge and collaboration capabilities, this mood has met the high level needs of graduate students and produces a very good incentive effect.

3) Research team incentive can enhance the self awareness of graduate students, improve their satisfaction and accomplishment.

Most of the students are limited by the conditions, especially with the expansion of the scale of the graduate students in recent years, the need for a number of graduate students' basic life support is not fully satisfied. Some of the students' needs are still at the level of physiology and survival.At the same time, as the highest degree of education, the students' need are complex. One of the responsibilities of educators is to guide the majority of graduate students have a high level of pursuit.High level pursuit, like "respect demand", "self fulfilling demand", which is consistent with the requirements of the cultivation "ideal, culture and discipline of the socialist successor".The spirit and value of academic motivation precisely conform to the needs of the graduate students, the incentives will long-term impact on their research initiative and creativity, the students often take this as a new starting point, they will have a strong interest in scientific research, science and technology invention, their talent and potential have fully played, they continue to achieve new progress and even to take the scientific research as their lifelong career. Even if they can't be engaged in scientific research, they can train their scientific and comprehensive quality, this is the unique role of academic motivation, which is the main difference between the academic motivation of graduate students and other scientific workers[3].

\section{INCENTIVE STRATEGIES APPLIED TO GRADUATE STUDENTS IN UNIVERSITY RESEARCH TEAM}

\section{A. Material incentive}

Material incentives include basic living allowances and scholarships, etc.. It is the most basic means of encouragement, as more living allowance is the lowest need of the graduate students. Material incentive evaluation also affected the work, study, life and other aspects of the students. Material incentive is the means to stimulate the students to study hard and participate in research work, it is mainly formed with positive incentives, such as subsidies, scholarship applications and the like; negative incentives, such as penalties. For graduate students in the research team, these external means constitute the most basic motivation of team work [4][5].

\section{B. Work design incentive}

The work design incentive of the graduate students mainly refers to enhancing the challenge of work, it can be achieved through job rotation and job enrichment. When students feel that the existing work is no longer challenging, the teacher can turn him to another more challenging work that at the same level and the similar technology.

The rich content of job rotation can reduce the boring sense of the work, and urge the students to work actively. In the completion of the above process, the sense of accomplishment, the sense of identity and responsibility are enhanced. The more effective way is to implement the task combination, the existing piecemeal tasks together, constitute a natural unit of work, and increase the diversity of skills and the integrity of the task, so that the graduate students realize the results of the work, the meaning and importance.

\section{Model incentive}

Each student in the team has a learning ability, each outstanding teacher or student can set an example, in particular the teacher's personal charm shows a very large influence. Because of the lack of experience in the study and research work, the graduate students need to learn from the experienced teachers in usual work, through the power of example to motivate themselves forward; many of the team's teachers are showing the personal charm in all aspects of their practical work. Graduate students can follow their example, exchange experience in the organized seminars and other channels, and learn how to do scientific research and how to publish a high level scientific article. The professors and the young promising teachers have a great effect on the graduate group. In a research team, all teachers should be strict with themselves and set up a flag for the students. 


\section{Academic innovation incentive}

At present, students' graduation requirements are more and more high, mainly reflected in the research work and publication of academic papers. The disadvantages of the traditional evaluation system is the excessive attention to the results of the academic innovation, the mechanism is rigid and unfair, which limits the academic innovation space of some professional graduate students; the academic innovation is slightly less. Therefore, the academic innovation incentive form need to change fundamentally, we need to build a scientific and reasonable evaluation and assessment mechanism Scientific and reasonable academic evaluation mechanism should be based on the principle of human principle, fair principle and dynamic principle, the dynamic factors, risk factors, and elasticity of the academic research are integrated into the evaluation system, the classification evaluation and assessment should also taken into consideration according to the different disciplines to ensure the balance and stability.

In order to make the students have a better innovation chance, colleges and universities should hold various forms of academic exchange and academic practice, while encourage graduate students to participate in academic conferences and seminars, cultivate the independent thinking and strengthen exchange among different subjects, continuously promote the academic innovation capabilities. In addition, we should improve our country's intellectual property protection laws and regulations, the collaborative innovation development and the union training and other ways to enhance the mutual trust between the university and the graduate students, improve the academic innovation and sharing platform of graduate students[6].

\section{E. Personal growth and development incentive}

As the young man who is about to enter the society, the graduate students have some confusions about the career planning and development of the individual. Teachers in scientific research team should help the students to make their own career planning and fully understand the willing of the individual growth and career development; help them to understand their own personality, their own professional and potential, to help students understand the team's development goals, the team's strengths and future prospects, to provide opportunities for them; to make the students understand the development of the society, the latest research direction and so on. At the same time, the graduate students should have a reasonable design of their careers, avoid unrealistic expectations and prevent the negative consequences[7].
Effective career design requires that individuals and organizations cooperate with each other, the research team should design different training program according to different professional planning, improve the level of research team and develop high-quality graduate students.

\section{CONCLUSIONS}

This article aiming at the reality of graduates and research team, describes and analyzes the individual needs of graduates in research team and the significance of incentive, explore the necessity and possibility of taking incentive strategies on graduate groups. The scientific research team as a platform, graduate students' individual needs as the starting point, the graduate featured incentive strategies in China's scientific research teams are explored. In order to fully mobilize graduate students' enthusiasm for learning and research, give full play for the innovation and potential graduate group and steadily improve the quality of graduate training.

\section{ACKNOWLEDGMENT}

This research was financially supported by the National Natural Science Foundation of China (No.51305112).

\section{REFERENCES}

[1] YUAN Fang, "Research on the Incentive Mechanism Optimization of Universities' Graduates", Journal of Qinghai Normal University(Philosophy and Social Sciences Edition), Vol. 35, pp. 153 155, 2013. In Chinese.

[2] SONG Da-wei, QIAN Hai-ming, "Analysis of the Constituent Elements and the Efficacy in Graduate Incentive Mechanism", Higher Education Forum, Vol. 11, pp. 106-108, 2009. In Chinese.

[3] YIN Yi-ming, MA Wen-shuo, LIU Ying, LIU Hai-tao, ZHANG Fei, "The important significance of the incentive mechanism in graduate education", Education Teaching Forum, Vol. 2, pp. 208-209, 2014. In Chinese.

[4] FAN Hua, LIU Jian-xing, "Discussion on Scholarship as Psychological Incentive for Graduate Students: a Case Study for Xiamen University", Journal of Graduate Education, Vol. 20, pp. 68-72, 2014. In Chinese.

[5] DENG Yu, XU Ya-nan, LI Yi, "Exploration about the Incentive Systems of College Graduates Scholarship", Journal of East China Institute of Technology(Social Science), Vol. 28, pp. 405-407, 2009. In Chinese.

[6] TONG Lin-jie, MENG Wei-dong, GUO Pei, "Research on the innovation incentive mechanism of graduate students in academic ecology". Academic Degrees and Graduate Education, Vol. 3, pp. 62-66, 2014. In Chinese

[7] CHEN Lei, JIANG Yang, ZHONG Hong-hai, CHEN Shi-fu, "Evaluation and Encouragement of Graduates' Scientific and Technological Achievements". Journal of Huaibei Normal University(Natural Science Edition ), Vol. 34, pp. 78-83, 2013. In Chinese. 